\title{
Tingkat Pencemaran Udara di Desa Silo dan Pace, Kecamatan Silo, Kabupaten Jember dengan Menggunakan Lichen Sebagai Bioindikator
}

\author{
(Level of Air Pollution in Silo and Pace Villanges, Silo Districts, Jember \\ by Using Lichen as Biodicator)
}

\author{
Septian Theo Fandani, Hari Sulistiyowati, Rendy Setiawan \\ Jurusan Biologi, Fakultas Matematika dan Ilmu Pengetahuan Alam, Universitas Jember (UNEJ) \\ Jln. Kalimantan 37, Jember 68121 \\ E-mail: theo.fandani@gmail.com
}

\begin{abstract}
Abstrak
Polusi udara dapat menurunkan kualitas lingkungan yang berdampak pada masalah kesehatan. Sumber utama yang menyebabkan masalah tersebut adalah terganggunya gas atmosfer yang berasal dari kendaraan roda empat, kendaraan roda dua, dan gas buang industri. Salah satu upaya monitoring kualitas udara adalah dengan menggunakan lichen. Lichen seringkali dijadikan indikator kualitas udara, karena organisme ini mempunyai sifat akumulator dan sangat adaptif terhadap perubahan lingkungan. Penelitian ini dilaksanakan untuk menentukan tingkat pencemaran udara di Desa Silo dan Pace. Kecamatan Silo. Metode sampling yang digunakan adalah dengan mengambil sampel lichen menggunakan plot-plot yang diletakkan secara vertikal pada pohon di tiga stasiun berbeda pada waktu yang hampir bersamaan. Tiga stasiun tersebut berada di Desa Silo, Pace, dan perkebunan Pace. Data yang didapat berupa nama jenis, jumlah koloni dan luas penutupan lichen untuk menentukan nilai IAP (Index of Atmospheric Purify). Hasil dari perhitungan IAP menunjukkan bahwa tingkat pencemaran udara di Desa Silo lebih tinggi daripada di Desa Pace dan perkebunan Pace. Hal ini dikarenakan Desa Silo memiliki nilai IAP yang lebih rendah $(10,58)$ dibandingkan dengan di dua stasiun lainnya (nilai IAP 30,84 dan 81,28). Tingginya pencemaran udara tersebut disebabkan oleh tingginya volume kendaraan bermotor yang melewati jalan di Desa Silo (2.530 smp/jam/lajur).
\end{abstract}

Kata Kunci: Biindikator, IAP, kualitas udara, Lichen.

\section{Abstract}

Air pollution can decrease the quality of environment giving impact on health problems. The main cause of those problems is high atmospheric gaseous either from vehicles, motorcycle, or industries. One method to monitor the air pollution level is using bioindicator, such as lichen. Lichens can be used as an indicator of air quality, because these organisms are good accumulators and highly adaptive to environmental changes. The aim of this research study was to identify the level of air pollution in Pace Plantation, Silo and Pace Villages. This research study was done by taking lichen samples at three different stations. Plotting method of trees at three stations were used to collect lichens. The data obtained were the colony number and species name of lichen which were then analyzed by using the IAP (Index of Atmospheric Purify) formula. The results of the IAP analysis showed that the level of air pollution in Silo Village was higher than that of in Pace Village and Pace Plantation area. It was because Silo Village had the lowest IAP value (10,58) comparing to other locations (IAP values 30,84 and 81,28). The high air pollution at Silo Village was influenced by the high volume of vehicles and motorcycles passed by its road.

Keywords: Bioindicator, Silo Village, IAP, Lichen.

\section{PENDAHULUAN}

Udara merupakan campuran dari beberapa gas terutama nitrogen, oksigen, dan karbon dioksida dan sebagian kecil lainnya terdiri dari helium, metana, dan hidrogen [1]. Udara tergolong bersih apabila proporsinya tidak berubah secara signifikan, namun jika terdapat perubahan pada proporsinya maka udara dapat dikatakan tercemar. Perubahan ini terjadi karena adanya zat pencemar yang terlepas ke udara. Zat pencemar ini dapat berasal dari kegiatan alam seperti gunung meletus, pembusukan makanan, atau debu yang terbawa angin, dan dapat pula berasal dari kegiatan manusia seperti gas buang cerobong asap dan gas buang kendaraan bermesin.

Secara global, gas buang kendaraan bermesin berkontribusi membuang polutan paling besar ke udara, yaitu $44 \%$ TSP, $89 \%$ hidrokarbon, $100 \% \mathrm{~Pb}$, dan $73 \% \mathrm{NO}_{\mathrm{x}}$
[2]. Polutan tersebut memberi dampak yang buruk bagi kesehatan manusia, terutama bagi wanita hamil, bayi, dan orang tua.

Desa Silo merupakan salah satu desa di Kecamatan Silo Kabupaten Jember yang dilalui oleh jalan provinsi lintas selatan, yang tiap jamnya dilewati sekitar 2.500 kendaraan. Jumlah kendaraan ini berbanding lurus dengan jumlah emisi yang dikeluarkan yaitu sebesar 551,3 g/menit [3]. Tingginya polusi udara oleh emisi kendaran ini perlu dimonitoring untuk memperoleh informasi level kualitas udara di area ini. Salah satu metode monitoring level kualitas udara adalah dengan menggunakan bioindikator.

Lichen merupakan salah satu organisme yang dapat dijadikan bioindikator, karena organisme ini bersifat akumulator dan sangat adaptif terhadap perubahan lingkungan [4]. Kedua sifat ini pula yang membuat 
keberadaan lichen sangat tergantung pada kondisi lingkunganya [5]. Salah satu indeks yang dapat menginterpretasikan kualitas udara dari keberadaan lichen adalah IAP (Index of Atmospheric Purify).

IAP merupakan indeks yang digunakan untuk menentukan tingkat kemurnian atmosfir dengan menggunakan data jumlah koloni lichen dan luas penutupannya sehingga nilai indeks ini dapat dihitung dengan persamaan 1 .

$$
\text { I } A P=\frac{1}{100} \sum_{1=i}^{n}\left(Q_{i} \times f_{i}\right)
$$

dengan Q sebagai indeks ekologis dan $f$ sebagai frekuensi penutupan [6]. Perhitungan ini sering digunakan untuk mengumpulkan informasi tentang toleransi bioindikator dalam hal ini lichen- terhadap polusi dan variasi kelimpahan spasialnya [7].

\section{METODE PENELITIAN}

Penelitian ini dilakukan selama bulan Januari hingga Maret 2017 di tiga stasiun berbeda di Kecamatan Silo yaitu di Desa Sempolan (stasiun 1) $\left(8^{\circ} 10^{\prime} 58.91^{\prime \prime S ~ \& ~}\right.$ $\left.113^{\circ} 52^{\prime} 16.28^{\prime \prime} \mathrm{T}\right)$, Desa Pace (stasiun 2) $\left(8^{\circ} 15^{\prime} 3.36^{\prime \prime S} \&\right.$ $113^{\circ} 51^{\prime 2} 23.68^{\prime \prime T}$ ), dan perkebunan Pace (stasiun 3) $\left(8^{\circ} 16^{\prime} 22.06^{\prime \prime S} \& 113^{\circ} 51^{\prime} 35.87^{\prime \prime T}\right)$. Sampling dilakukan di 10 pohon pada tiap stasiun di pinggir jalan raya sepanjang 500 meter, dengan menggunakan plot berukuran $10 \times 10 \mathrm{~cm}^{2}$ dan 3 kali pengulangan pada tiga arah mata angin. Setiap jenis species lichens yang belum diketahui namanya diberi kode dan diambil sampelnya untuk diidentifikasi lebih lanjut di laboratorium. Pada setiap plot, dihitung jumlah koloni dan luas penutupannya untuk dianalisis dengan menggunakan dengan rumus IAP.

Nilai yang didapat dari rumus tersebut kemudian di masukkan dalam kriteria IAP [8] untuk menentukan level pencemarannya (Tabel 1).

Tabel 1. Kriteria IAP

\begin{tabular}{ccc}
\hline $\begin{array}{c}\text { Tingkatan } \\
\text { pencemaran }\end{array}$ & Kriteria & Keterangan \\
\hline Level A & $0 \leq$ IAP $\leq 12,5$ & Polusi sangat tinggi \\
Level B & $12,5<$ IAP $\leq 25$ & Polusi tinggi \\
Level C & $25<$ IAP $\leq 37,5$ & Polusi sedang \\
Level D & $37,5<$ IAP $\leq 50$ & Polusi rendah \\
Level E & IAP $>50$ & Polusi sangat rendah \\
\hline
\end{tabular}

Penghitungan jumlah koloni dilakukan di lapang sedangkan penentuan luas koloni dilakukan di Laboratorium Ekologi Jurusan Biologi, Fakultas Matematika dan Ilmu Pengetahuan Alam, Universitas Jember. Identifikasi sampel sampai tingkat jenis dilakukan di Laboratorium Kriptogram Tumbuhan Rendah, LIPI, Cibinong, Bogor.

\section{HASIL DAN PEMBAHASAN}

\section{Keanekaragaman Jenis Lichen}

Berdasarkan hasil penelitian, pada stasiun 1 terdapat 21 jenis lichen, pada stasiun 2 terdapat 14 jenis, dan pada stasiun 3 terdapat 14 jenis lichen seperti yang terdapat pada Tabel 1 .
Tabel 2. Daftar nama jenis dan jumlah koloni lichen pada tiap stasiun

\begin{tabular}{|c|c|c|c|c|}
\hline \multirow[t]{2}{*}{ No } & \multirow[t]{2}{*}{ Nama Jenis } & \multicolumn{3}{|c|}{$\begin{array}{c}\text { Stasiun } \\
\text { (Jumlah koloni) }\end{array}$} \\
\hline & & 1 & 2 & 3 \\
\hline 1. & Lepraria lobificans & 27 & 67 & 114 \\
\hline 2. & Physcia sp. & 107 & 80 & 138 \\
\hline 3. & Allograpa sp. & & 1 & 82 \\
\hline 4. & Cryptothecia scripta & 49 & 1 & 268 \\
\hline 5. & Pyreluna sp. & & & 218 \\
\hline 6. & Arthonia sp. & 12 & & 20 \\
\hline 7. & Pyrenula sp. & 6 & 8 & 2 \\
\hline 8. & Phaeographis sp. & 8 & 2 & 42 \\
\hline 9. & Leiorreuma sericeum & 2 & & 24 \\
\hline 10. & Allograpa sp. & 2 & & 43 \\
\hline 11. & Lecanora rupicola & 8 & 7 & 3 \\
\hline 12. & Pertusaria multipuncta & 22 & & 20 \\
\hline 13. & Trapeliopsis granulosa & 8 & 6 & 2 \\
\hline 14. & Graphis dendrograma & 6 & & 2 \\
\hline 15. & Lepraria sp. & 80 & 92 & \\
\hline 16. & Arthonia (cf) radiata & & 7 & \\
\hline 17. & Dirinaria picta & 19 & 4 & \\
\hline 18. & Graphis scripta & 11 & 6 & \\
\hline 19. & Lecanora (cf) tropica & 8 & 3 & \\
\hline 20. & Pyxine (cf) cocoes & 79 & 190 & \\
\hline 21. & Leptogium sp. & 7 & & \\
\hline 22. & Dyplolabia afzelii & 21 & & \\
\hline 23. & Dyorigma (cf) antillarum & 2 & & \\
\hline 24. & Flavoparmelia caperata & 1 & & \\
\hline & Total koloni : & 485 & 474 & 978 \\
\hline
\end{tabular}

Perbedaan jumlah koloni yang ditemukan pada tiap stasiun disebabkan oleh kemampuan adaptasi masingmasing jenis lichen terhadap kondisi lingkungan di stasiun tersebut. Selain itu, jenis talus lichen juga ikut menentukan toleransi organisme ini terhadap polutan yang ada pada lingkungan [12].

Stasiun 1 dan 2 memiliki koloni yang lebih sedikit jika dibandingkan dengan stasiun 3, hal ini disebabkan oleh volume kendaraan yang tinggi di kedua stasiun. Penelitian yang dilakukan oleh [10] dan [11] juga menunjukkan bahwa semakin tinggi tingkat polutan di suatu lokasi, maka jumlah koloni lichen semakin sedikit.

\section{Kondisi Lingkungan Abiotik}

Hasil penghitungan jumlah kendaraan menunjukkan bahwa jumlah kendaraan yang melewati stasiun 1 paling banyak (2.530 smp/jam/lajur) dibandingkan dengan stasiun yang lain. Jumlah kendaraan yang paling sedikit melewati jalan adalah stasiun 3 (290 smp/jam/lajur).

Pengukuran data abiotik khususnya untuk data temperatur, kelembaban, dan intensitas cahaya tidak dilakukan secara bersamaan dikarenakan keterbatasan alat, sehingga terdapat perbedaan hasil pengukuran [13]. Selain itu, perbedaan kanopi tanaman yang menjadi lokasi sampling berkontribusi terhadap perbedaan kondisi lingkungan di lokasi penelitian. Kerapatan kanopi pada stasiun 1 dan 2 cenderung lebih terbuka daripada kerapatan kanopi di stasiun 3, sehingga hal ini berdampak pada intensitas cahaya yang tinggi, temperatur yang tinggi, dan 
kelembaban yang rendah.

Kondisi lingkungan yang demikian, didapatkan kisaran data pengukuran abiotik yaitu 445,67-1300,97 lux untuk intensitas cahaya, $30,26-32,25^{\circ} \mathrm{C}$ untuk temperatur, dan $55,88-60,72 \%$ untuk kelembaban udara. Kondisi tersebut merupakan kondisi lingkungan yang optimal bagi pertumbuhan lichen, karena jika lebih tinggi atau lebih rendah maka akan mengganggu metabolisme photobiont dan dapat merusak jaringan medula mycobiont.

\section{Tingkat Pencemaran Berdasarkan Nilai IAP}

Berdasarkan hasil perhitungan IAP, didapatkan tingkat pencemaran seperti yang ada pada Tabel 3 .

Tabel 3. Tingkat pencemaran tiap stasiun berdasarkan IAP

\begin{tabular}{cccc}
\hline Lokasi & $\begin{array}{c}\text { Tingkat } \\
\text { pencemaran }\end{array}$ & $\begin{array}{c}\text { Nilai } \\
\text { IAP }\end{array}$ & Keterangan \\
\hline Stasiun 1 & Level A & 10,58 & Polusi sangat tinggi \\
Stasiun 2 & Level C & 30,84 & Polusi sedang \\
Stasiun 3 & Level E & 81,28 & Polusi sangat rendah \\
\hline
\end{tabular}

Perbedaan level kemurnian atmosfer pada tiap stasiun yang ditunjukkan pada Tabel 1 disebabkan oleh tingkatan polusi yang berbeda, khususnya yang terkait dengan volume kendaraan yang melewati jalan raya. Dampak volume kendaraan yang tinggi adalah jumlah koloni lichen, sehingga berpengaruh pula terhadap nilai IAP pada masingmasing stasiun.

Stasiun 1 memiliki nilai IAP yang rendah yaitu sebesar 10,58 karena memiliki volume kendaraan yang tinggi, yaitu sebanyak $2.530 \mathrm{smp} /$ jam/lajur. Hal ini dikarenakan hanya lichen yang toleran terhadap polutan tinggi yang dapat hidup. Pada penelitian [6] dan [9], menunjukkan bahwa lokasi-lokasi yang tercemar polutan memiliki lichen yang lebih sedikit jumlahnya daripada lokasi yang masih belum terlalu tercemar.

Sebagai pembanding, stasiun 2 mempunyai nilai IAP yang lebih besar dari stasiun 1 yaitu 30,84 karena jumlah volume kendaraan pada stasiun ini lebih sedikit dibanding stasiun 1 yaitu $1.239 \mathrm{smp} / \mathrm{jam} / \mathrm{lajur}$. Hal ini dapat dijelaskan bahwa volume kendaraan berbanding terbalik dengan jumlah koloni yang ditemukan. Selain itu, kemampuan adaptasi setiap jenis lichen juga berbeda-beda, khususnya terhadap level cemaran yang tinggi. Hal ini ditunjukkan dengan sedikitnya koloni lichen di stasiun 1, yaitu sebanyak 485 koloni.

Pada stasiun 3 yang juga merupakan stasiun kontrol, memiliki volume kendaraan sebesar $290 \mathrm{smp} /$ jam/lajur. Hal ini berdampak pada besarnya nilai IAP yang didapat $(81,28)$ dan banyaknya perjumpaan koloni lichen di stasiun ini, karena kualitas udara pada stasiun ini cenderung lebih bersih jika dibandingkan dengan stasiun 1 maupun stasiun 2.

\section{KESIMPULAN}

Hasil dari perhitungan IAP menunjukkan bahwa tingkat pencemaran udara di Desa Silo lebih tinggi daripada di Desa Pace dan perkebunan Pace. Hal ini dikarenakan Desa
Silo memiliki nilai IAP yang lebih rendah $(10,58)$ dibandingkan dengan di dua stasiun lainnya (nilai IAP 30,84 dan 81,28). Tingginya pencemaran udara tersebut disebabkan oleh tingginya volume kendaraan bermotor yang melewati jalan di Desa Silo (2.530 smp/jam/lajur).

\section{UCAPAN TERIMA KASIH}

Terimakasih kepada Laboratorium Ekologi Jurusan Biologi FMIPA Universitas Jember dan Laboratorium Kriptogram Tumbuhan Rendah LIPI Cibinong.

\section{DAFTAR PUSTAKA}

[1] Tjasyono, B. 2006. Meteorologi Indonesia I : Karakteristik dan Sirkulasi Atmosfer. Jakarta: Badan Meteorologi dan Geofisika.

[2] Budiyono, A. 2001. Pencemaran Udara: Dampak Pencemaran Udara Pada lingkungan. Berita Dirgantara. 1 (2): 21-27.

[3] PERMENLH. 2010. Peraturan Menteri Negara Lingkungan Hidup Nomor 12 Tahun 2010 Tentang Pelaksanaan Pengendalian Pencemaran Udara di Daerah. Jakarta: MENLH.

[4] Hardini, Y. 2010. Keanekaragaman Lumut kerak di Denpasar Sebagai Bioindikator Pencemaran Udara. http://limnologi.lipi.go.id/katalog/index.php/searchkat alog/byId/476. [Diakses pada 29 Februari 2016].

[5] Roziaty, E. 2016. Kajian Lichen: Morfologi, Habitat, dan Bioindikator Kualitas Udara Ambien Akibat Polusi Kendaraan Bermotor. Bioeksperimen. 1 (2): 5466.

[6] Das, P., S. Joshi, J. Rout, dan D. K. Upreti. 2013. Lichen diversity for environmental stress study: Application of index of atmospheric purity (IAP) and mapping around a paper mill in Barak Valley, Assam, northeast India. Tropical Ecology. 54 (3): 355-364.

[7] LeBlanc, S. C. F. dan Sloover, J. D. 1970. Relation between industrialization and the distribution and growth of epiphytic lichens and mosses in Montreal. Canadian Journal of Bot. 48: 1485-1496.

[8] Conti, M. E. dan Cechetti, G. 2001. Biological Monitoring: Lichen as Bioindicator of Air Pollutiont Assassement - a review. Environmental Pollution. 114 (2001): 471-492.

[9] Attanayaka, A. N. P. M. dan Wijeyaratne, S. C. 2013. Corticolous Lichen Diversity, A Potential Indicator For Monitoring Air Pollution In Tropics. Journal of the National Science Foundation of Sri Lanka. 41 (2): 131-140.

[10] Pryanka, A. 2014. Keanekaragaman Lumut Kerak Tiga Taman Kota di Jakarta Selatan Sebagai Bioindikator Pencemaran Udara. Bogor: IPB Press.

[11] Laksono, A. 2016. Identifikasi Jenis Lichen Sebagai Bioindikator Kualitas Udara di Kampus Institut Agama Islam Negeri Raden Intan Lampung. http://repository.radenintan. ac.id/209/. [Diakses pada 7 Juni 2017].

[12] Roziaty, E. 2016. Kajian Lichen: Morfologi, Habitat, dan Bioindikator Kualitas Udara Ambien Akibat Polusi Kendaraan Bermotor. Bioeksperimen. 1 (2): 54 66. 
[13] Patil, G. P. 2014. Composite sampling. Wiley StatsRef: Statistics Reference Online. 1 (1): 1-6. 